\title{
O eu na auto-ornamentação ${ }^{1}$
}

Marilyn Strathern ${ }^{2}$

Tradução: Beatriz Braga, Janaina Tatim, João Roberto Bort Jr. e Lucas da Costa Maciel

Quando Huxley (1971) resenhou nosso livro Self-decoration in Mount Hagen (1971) para a Ink, ele o fez atentando também para outro livro: The Beautiful People's Beuty Book, or How to achieve the look and manner of the world's most attractive women, da Princesa Pignatelli. Ao discutir as recomendações da Princesa de que uma mulher deveria sempre usar maquiagem, Huxley comenta que um efeito desse elaborado estratagema é colocar as coisas fora de alcance com intuito de torná-las mais atraentes. Ele aplica às preocupações da Princesa a explícita noção Hagen de que as ornamentações atraem riqueza: seu autoadornar-se "atrai interesse, e dado que interesse é o que o dinheiro gera, ela deve precisar de muito dinheiro para permanecer bela. Porém, se está fazendo isso para si mesma, ela deve estar tentando competir com seu próprio reflexo" (1971:17).

Se competir com o próprio reflexo está no cerne da cosmética, poderia ser útil pensar a auto-ornamentação Hagen como um ato cosmético?

Em nossa própria cultura, cosméticos embelezam o corpo. Estão envolvidos valores estéticos, um senso de estilo e contexto, e o objetivo explícito de realçar o indivíduo. Ao dispor a pessoa em um estilo particular, belo em si mesmo, ele ou ela também se torna mais bonito do que estando sem adornos. Assim como as mensagens sociais transmitidas no estilo, os efeitos da personalidade podem ser buscados para se parecer mais atraente, impactante, delicado, e por aí em diante. Em contraste com os Hagen, pensamos que se embelezar é mais apropriado às mulheres do que aos homens. Nesse contexto, feministas ressaltaram que, à medida em que se coloca a atenção no ato de embelezamento, ela é tirada do indivíduo enquanto pessoa. Assim, modas que possuem o propósito explícito de tornar o indivíduo sexualmente atraente são tomadas por Greer (1970: 57f) como vilãs por simplesmente transformarem a pessoa em um objeto sexual. Quanto mais o estilo cosmético incorpora cânones convencionais de gosto, mais ele cria um objeto. O realce de aspectos da pessoa - beleza facial, atributos sexuais - é tomado como uma depreciação do todo. A mulher

1 O artigo, originalmente em inglês, foi publicado em Strathern, Marilyn. 1979. "The Self in Self-Decoration". Oceania 49 (4) jun.: 241-257. http://www.jstor.org/stable/40332210.

2 Professora da Universidade de Cambridge e Doutora em Antropologia pela mesma instituição. E-mail: ms10026@cam.ac.uk

3 Eu agradeço Andrew Strathern por debater vários dos pontos indicados neste trabalho, que segue adiante sua interpretação de Why is shame on the skin? (Strathern, A., 1975a); Gillian Gillison e também membros do Seminário de Cultura Material do Departamento de Antropologia, Universidade College London, comentaram de forma útil uma versão anterior. 


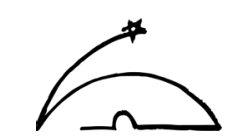

se torna nada além do embelezamento. Por isso, ocorre às pessoas se adornarem de uma maneira pouco convencional a fim de expressar o que reclamam que o estilo esconde: sua personalidade.

Essa visão em particular nutre o paradoxo de que o processo de embelezamento, por meio do qual um indivíduo espera melhorar a si mesmo, pode, na realidade, diminuir o valor de sua individualidade. Trata-se de mais do que simplesmente o fato de que o realce, aos olhos dos outros, pressupõe idiomas compartilhados e, portanto, generalizados de beleza. Se as pessoas que utilizam cosméticos adotam ou não uma visão holística de si mesmas, seus críticos estão se debatendo com um contraste entre corpo e alma, entre aparência física e individualidade, entre uma superfície externa e uma identidade interna. Essa abordagem crítica à cosmética faz sentido apenas se o ato do embelezamento se aplicar somente ao corpo. Nesse contexto, a pele, a superfície externa, é verdadeiramente superficial, trivial em relação à identidade pessoal. E, em primeiro lugar, a cosmética atende à superfície do corpo e suas características.

A mesma atenção parece ser o foco da "arte pessoal" dos Nuba (Faris, 1972). Os Nuba se preocupam com a forma como seus eus físicos são apresentados em público; motivos gráficos e estilos refletem algo sobre a posição social dos atores, mas o conteúdo em questão é o corpo em si mesmo: "a exposição decorada" (1972: 54). Talvez Gell tenha isso em mente quando critica Self-decoration por negligenciar o simbolismo do corpo e falhar em fornecer uma descrição coerente da teoria hagen do corpo. Ele sugere que as ornamentações são "em último recurso apenas acessórios ao próprio corpo do ator, que é o que está realmente sendo exibido" (: 684). Mas, nesse caso, o meio também é a mensagem?

É relevante a descrição de Munn (1973) da arte walbiri. Um importante grupo de ornamentações [designs], ao qual os homens walbiri iniciados têm direitos, pode ser reproduzido em uma variedade de meios, em trajes cerimoniais, no chão, em painéis, pedras, armas, e no corpo. O corpo como meio possui seu próprio significado. Grafismos que podem ser anexados ou que podem entrar em contato com o corpo possuem um conteúdo particular, envolvendo a obtenção de finalidades físicas - nesse caso, bem-estar e fertilidade, e, no caso de outros grafismos, crescimento das crianças e atração de amantes. Ainda assim há continuidade entre o uso de outros itens e o corpo em si. Em certo sentido, o corpo é uma superfície para imagens que podem ser graficamente imaginadas e reproduzidas em outras superfícies.

Os Hagen não produzem ornamentações padrões [standard designs] do tipo walbiri. Suas ornamentações têm um elemento cosmético a medida em que não possuem outro contexto além do corpo. Ornamentos são pendurados no corpo, suas diferentes partes recebendo ênfases particulares: cabelo, rosto, braços, peitos e costas, e as partes pubianas são todas decoradas de maneira distintiva. A composição não pode ser montada em nenhum outro meio. Ademais, os Hagen são cientes do paradoxo cosmético de que o embelezamento pessoal pode desviar a atenção da pessoa. Mas para eles isso é um efeito almejado conscientemente. Eles enfatizam que, enquanto grupo, quando se vestem com penas, pinturas e folhas, a primeira coisa que os espectadores devem ver é a ornamentação - assim, descobrir o indivíduo por trás dela se torna um choque prazeroso. Eles 
não estão se vestindo com fantasias, assumindo a forma de um animal ou espírito; eles não estão usando máscaras, encenando mitos ou performando dramas. Eles não estão fingindo ser alguém além deles mesmos, mas eles mesmos paramentados a ponto de se disfarçarem. Essa ideia é incorporada especificamente à estética: um dançarino reconhecido à primeira vista se ornamentou mal.

O objeto do disfarce hagen é a identidade da pessoa tal qual conhecida por suas características físicas. Aqui há um contraste fundamental com aqueles sistemas cosméticos cujo objetivo não é o disfarce, mas o realce - de acordo com o estilo predominante - da beleza pessoal do ator. Seu foco é o corpo em particular, cujos atributos são encarados como uma forma de recurso. Assim, os Nuba demonstram uma requintada preocupação com contorno e forma em sua série de termos anatômicos para diferentes estruturas corporais (Faris, 1972: 65-6). Marcas físicas são escondidas com interesse em ressaltar os pontos positivos de um corpo. Em nossa cultura, imperfeições corporais, uma questão de estigma a partir de alguns pontos de vista, são pensadas como uma parte mais intrínseca da pessoa do que os atributos idealizados.

Os Hagen exploram o paradoxo cosmético em um sentido oposto: eles não acreditam que ornamentar o corpo esconde o eu interno. Eu argumentaria que o corpo físico é disfarçado por ornamentações precisamente porque o eu é uma de suas mensagens.

\section{Arte e celebração de conquistas em Hagen}

O povo Hagen possui pouca arte convencional, a maior parte dela decorativa, sendo o corpo humano o principal objeto de ornamentação. O adorno é um aspecto do vestir-se: de modo mais simples, alguém se arruma para receber um visitante, colocando uma peruca ou alisando seu avental, ao passo que, mais formalmente, se veste com um conjunto específico de penas, folhas e conchas, passa óleo no peito e pinta o rosto, com semanas ou meses de dedicação para reunir o conjunto apropriado.

Interessa-me o significado de certas ornamentações formais usadas pelos homens. A formalidade deve ser encontrada nos requisitos de estilo, julgamentos feitos sobre o efeito estético, e na autoconsciência dos atores que estão em exibição. Apresentações deliberadas da pessoa decorada para uma audiência congregada enquanto testemunhas caracterizam apenas certas ocasiões celebrativas. Nessas, os homens de um clã, ou subclã, se juntam para celebrar alguma conquista, como a apresentação de um presente moka (troca cerimonial) ou de uma performance de culto. Em outros momentos, os Hagen se ornamentam em estilos especiais, como para grandes funerais ou combates, porém não há audiência em sentido específico - apenas outros atores envolvidos no evento. E enquanto há muitas situações menores em que as pessoas se vestem a fim de impressionar outras, como em frente a novos afins em um pagamento do dote de uma noiva ou meninas em uma festa de cortejo, tais ornamentações são uma questão de gosto individual, um acessório à maneira como o ator se apresenta em vez do foco. O que distingue as celebrações é que, por um período, ao longo dos procedimentos, as ornamentações em si se tornam o centro da

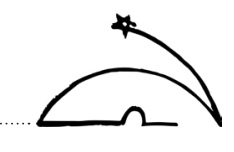




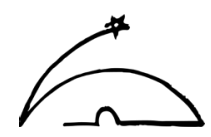

atenção. São exibidas à audiência, talvez por duas horas aproximadamente, por meio da dança. O movimento - em geral mínimo, nada além, em certos casos, de um balanceio para cima e para baixo - é projetado para mostrá-las ao máximo efeito.

Vestir-se deve sempre veicular mensagens, e se assumimos que estamos lidando com um sistema coerente, o significado não pode ser compreendido por meio do isolamento aleatório de uma classe particular. No entanto, meu interesse não está no simbolismo do estilo, mas no ato da exibição.

Conquistas de certo tipo possuem valor categórico na cultura hagen; acima de tudo, a aquisição de riqueza e a demonstração de influência trazem prestígio aos homens e os tornam grandes. A capacidade para conquistas é uma questão pessoal, mas para que o sucesso de um indivíduo tenha significado público, ele depende do envolvimento de seus companheiros de clã, seja se enquanto um big-man mostra suas capacidades organizacionais, seja se simplesmente participa de empreendimentos conjuntos que afetarão as relações do grupo com outros ao redor. Ocasiões de exibição formal são sempre preocupação de um grupo, e o que é exibido é a soma do esforço individual - não os cálculos financeiros e as maquinações através das quais coisas de valor são obtidas, não as estratégias políticas que mantiveram o grupo reunido ou o secreto assassinato de inimigos que protegeu seus números, mas o fim desses meios: riqueza, força e poder. Um clã apenas é bem-sucedido com o auxílio de seus membros ancestrais, e essas qualidades abstratas são concretizadas em uma demonstração da mais óbvia das dádivas que ancestrais concedem, saúde corporal e bem-estar.

Nas danças que se seguem às performances de culto, a atenção é particularmente direcionada para o bem-estar interno que o culto promete em termos de fertilidade do clã, pureza masculina, entre outros. A reivindicação pública de um grupo em relação a outros é o conteúdo explícito de danças moka. Mas essas são apenas ênfases. Estados internos e externos de bem-estar também estão em uma relação metafórica entre si. Assim, saúde corporal pode ser um símbolo para a força política do clã, e seu sucesso em transações de riquezas, um símbolo de espírito guerreiro. A proposta pode ser encarada do ponto de vista da maquiagem de uma pessoa. Ornamentações que atuam como meio de exibição para o clã adornam seus membros individuais. Esses mesmos ornamentos também manipulam uma distinção entre um eu interno e externo.

\section{Mensagens}

Resumo brevemente os tipos de mensagens veiculadas por meio das ornamentações usadas por doadores masculinos em um moka de grande importância. Apesar de performances de culto e festivais moka serem ambos momentos de celebração, ornamentações de culto envolvem elementos especiais que não podem ser elaborados aqui, e meu argumento é direcionado principalmente às ornamentações usadas nas trocas. 
As ornamentações hagen não são fantasias, conjuntos de roupas que possam ser vestidas inteiramente, mas composições cuidadosamente arranjadas e rearranjadas a cada evento de maior proporção. Tampouco incluem regalias, símbolos de cargos públicos, por não haver tais cargos, mas apenas pessoas em determinados papéis (e.g. doadores) ou pretendentes a um status particular (e.g. big-man). Doadores são distinguidos de outros dançarinos pela completude de seu traje ou pelo uso de adornos de cabeça especiais. Aqueles que dançam juntos concordam em adotar um estilo particular a partir de um pequeno conjunto de opções determinadas pelo tipo e magnitude da situação. Detalhes estilísticos também são associados a certas regiões, mas não há a ideia de nenhum grupo ou categoria de pessoas que possuem direitos sobre as ornamentações [designs]. Dentro dos limites do estilo escolhido para a ocasião, os big-men podem se destacar por alguma excentricidade de vestuário, e todos os participantes preparam suas próprias composições, cujos detalhes variam de acordo com o gosto individual. A impressão final é uma de solidariedade ao invés de uniformidade.

\section{(ii) Representando emoções e atitudes}

Os dançarinos em exibição expressam certas emoções padronizadas: portanto, diz-se que uma faixa vermelha no rosto indica sua confiança e assusta os espectadores. Eles brandem armas e cobrem a parte superior do corpo e do rosto com carvão para darem uma aparência aterrorizante e bélica. Declarações políticas também podem ser direcionadas a setores da audiência. Comumente referem-se a uma ostentação ou desafio vencido, e irão se relacionar aos detalhes de aliança e rivalidade intergrupal que apenas alguns poucos conhecem (e.g. alguém pode segurar folhas de batata doce para responder ao insulto de que seu espaço cerimonial não serviria para além do crescimento de vegetais). Tais gestos são paralelos ao discurso velado que caracteriza a oratória formal que acompanha as transações públicas (Strathern, A. J., 1975b). Os sentimentos assim expressos são todos pública e abertamente sustentados, mas generalizados; os dançarinos podem adquirir uma postura agressiva, porém o que pode ser alvo particular de sua hostilidade está aberto à interpretação.

\section{(iii) Imagens de bem-estar}

Uma gama de declarações também é feita acerca do bem-estar dos dançarinos. Adicionalmente à riqueza exibida de fato na área cerimonial, o grupo de doadores - tenham eles contribuído individualmente ou não - também usarão conchas valiosas como indicação de sua prosperidade. Saúde e força corporal devem ser vista na forma como a pele brilha com óleo. Fecundidade é associada a cores claras, e se a dança celebra especificamente a produção de porcos, as ornamentações são predominantemente brancas, comparadas ao brilho da gordura do porco. O sucesso em geral e a força são ainda mais demonstrados na medida em que as ornamentações alcançam um efeito desejado. Itens são arranjados com uma interação de contrastes entre elementos 


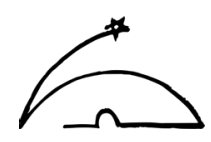

claros e escuros, enquanto estilos específicos podem demandar uma ênfase em uma direção ou outra. Assim, espectadores podem comentar que um conjunto é "muito escuro" ou "muito claro".

Essas mensagens são todas explícitas nas mentes dos atores, que lutam para criar certos efeitos que produzirão reações na audiência. Os Hagen não dançam à noite, pois o ponto é que sejam vistos. Em várias ocasiões, as pessoas comentaram que a razão para paramentarem-se é "para que outros saibam" que eles fizeram o moka propriamente ou que criaram muitos porcos, e "as pessoas vão criar histórias sobre nós". Não é suficiente transferir riqueza, criar discursos: as ornamentações também darão ao clã sua reputação. Se há uma necessidade de ser visto, então o que está se fazendo visível?

Olhe novamente para as imagens de bem-estar. Essas contrastam significativamente com outras mensagens, pois mesmo que qualidades como prosperidade ou sucesso possam ser reivindicadas pelos atores, elas nunca podem ser mais que reivindicações. Nessa sociedade, um grande valor é colocado na conquista, porém não há maneira pela qual ela possa ser institucionalizada ${ }^{4}$; prestígio é sempre relativo e, ao final, deve estar nos olhos dos outros. O máximo possível é estar constantemente produzindo evidências para as reivindicações de alguém.

Quando primeiro usamos o termo auto-ornamentação, foi para chamar atenção ao fato de que a conquista do grupo é vista como dependente dos esforços pessoais de seus membros individuais, de forma que integrantes de um clã que celebram um triunfo conjunto estão celebrando a si mesmos. Aqui sugiro, ademais, que certos aspectos do eu são expressados em tais exibições, e que isso está amarrado à natureza das reivindicações. Se um clã está fazendo visível sua força e riqueza, esses são atributos que indivíduos também demonstram. Ao usarem a si mesmas para significar suas próprias conquistas, as pessoas se revestem com essas qualidades e atributos.

\section{Ansiedade e estética}

Um conjunto dentre as várias declarações que as ornamentações hagen sugerem refere-se às emoções do ator. Essas estão relacionadas ao ambiente social e político (sentimentos de triunfo, agressividade), e a um senso de bem-estar interior, que é mostrado por meio da beleza corporal. A beleza não se encontra na ênfase de características pessoais, pois a identidade individual física é disfarçada ${ }^{5}$, mas na exibição de certas qualidades que o grupo como um todo apresenta. Logo, um efeito geral da ornamentação é fazer o corpo parecer grande e alto, e há uma magnificação correspondente da pele ${ }^{6}$ ao ser besuntada para ficar com um brilho lustroso. A cabeça é aumentada com perucas, penas, faixas com pelos; e no rosto são pendurados ornamentos que o escurecem.

4 A não ser que consideremos, nessa perspectiva, sua correlação dogmática com gênero (ver Strathern, M., 1978).

5 Ou parcialmente disfarçada. Não é que a identidade deva ser mantida em segredo, mas que as decorações devem ser vistas primeiramente por si mesmas. Parte da diversão, certamente para os membros mais jovens da plateia, encontra-se em identificar os dançarinos.

6 Nota de tradução: no original, o termo é "flesh", podendo ser traduzido como "carne". No entanto, como a autora explicará sobre os sentidos de "pele" a partir da Papua Nova Guiné, o termo apresenta essa dupla significação. 
É na sombra dessa profusão que se diz que espíritos ancestrais "vêm ao rosto dos homens" e os apoiam.

Essa exibição autoconfiante de poder é cercada de ansiedade. No passado, grandes performances sempre eram acompanhadas por sacrifícios para invocar o auxílio dos espíritos; e, hoje em dia, matam porcos com intenção similar para pagar parentes e parceiros que providenciaram alguns dos ornamentos. Os porcos são cozinhados separadamente na área particular das pessoas. As diferentes etapas de colocar e remover as decorações eram formalmente acompanhadas por presságios. (Nessas ocasiões, especialistas rituais ainda agem, ocasionalmente, como adivinhos.) Há três pontos significativos sobre os presságios. (i) Eles são conduzidos entre os membros de segmentos dentro do clã assim como entre grupos inteiros de dançarinos; (ii) afora esse pequeno conjunto de homens, indivíduos são selecionados como tendo um destino particular - um homem consegue pegar uma peça de inhame jogada no ar, outro é isolado porque o óleo não escorreu em linha reta ao ser virado sobre seus ombros; (iii) o presságio frequentemente relaciona-se a eventos para além do imediato sucesso da exibição: quem desses homens conseguirá tamanha impressão a ponto de meninas se juntarem em sua casa depois; alguns dos dançarinos ficarão doentes ou, mesmo possivelmente, morrerão? Bastante desassociada do sucesso do grupo, a exibição carrega significado, portanto, para a sorte futura de seus membros individuais.

Eu interpretaria o presságio como significação de um distanciamento que os atores receiam existir entre as reivindicações que fazem e o seu real estado. A ocasião parece celebrar algo já realizado, porém o sucesso do momento é julgado também por sua projeção no futuro. Os dançarinos teriam de fato evocado o apoio dos fantasmas? A presente conquista é um sinal de prosperidade geral, a força que o grupo desfila indicativo de um poder básico, as qualidades que os dançarinos reivindicam intrínsecas? Pois reivindicações podem ser sempre refutadas. Alguns homens de clãs podem falhar em futuras trocas, porcos podem morrer, homens adoecer.

Está em questão se o dançarino e seu grupo realmente possuem os atributos que afirmam ter. Por que meios é dada a prova? Presságios são um tipo de atalho para a resposta final, mostrando quem terá a boa sorte. Mas a exibição é, em si mesma, o maior teste: portanto, o significado da estética. Importa quão deslumbrante são os ornamentos, quão coordenada a dança, quão extasiante o efeito total, pois más ornamentações são em si um mau presságio, um sinal de que um infortúnio se seguirá.

As qualidades que um grupo parece anexar a si são em parte uma questão de recursos internos; ele solicita evidência de que os fantasmas ancestrais os apoiam. Força e riqueza também são, entretanto, relativas, pois é quando o clã se prostra respeitosamente diante de rivais e vizinhos que elas serão medidas. O reconhecimento de uma reivindicação encontra-se na opinião de outros, e aqueles em exibição torcem para deixar uma impressão específica nos espectadores, forçando-os à admiração e ao temor. Então o efeito desejado será alcançado. Portanto, a energia dos dançarinos concentra-se em uma projeção de si mesmos. Eles esperam influenciar as mentes dos espectadores. Porém, ainda que haja muitos comentários gratuitos sobre as ornamentações 


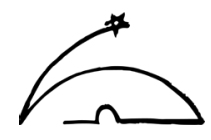

- sobretudo críticos - não há retorno formal, não há aplausos da plateia ${ }^{7}$. Isso ressalta o esforço a ser feito, pois não há acordo automático. A audiência será uma mistura diversa de inimigos e estranhos, bem como de amigos, e os dançarinos reivindicam não um novo status ou uma nova posição ritual ${ }^{8}$, mas superioridade acima dessas próprias pessoas. Não obstante, as ornamentações são feitas para produzir reações nos espectadores: eles devem ser atraídos pelas cores brilhantes, ameaçados pelas escuras, e assim por diante. Deles também se espera que julguem as montagens de acordo com critérios específicos. Pessoas são críticas se os itens são escassos, os elementos mal-arranjados e não propriamente equilibrados, o efeito total "muito escuro" ou "muito claro", dependendo do contexto, e se o indivíduo pode ser facilmente reconhecido. Tudo isso indica derrota e ausência de auxílio espiritual.

O ponto sobre quão facilmente um dançarino pode ser reconhecido foi uma constante repetição nos comentários de informantes sobre o que faz uma exibição ser bem-sucedida. Qual é o significado de suas insistências em que as ornamentações deveriam ser vistas antes de seus portadores?

As pessoas também se referem às ornamentações como o que é trazido para fora. Literalmente, os ornamentos são desempacotados de embalagens oleosas e enfumaçadas nas quais são normalmente escondidos, ou trazidos de uma densa e escura floresta, mas, mais do que isso, todo o drama da exibição é uma revelação, um tornar público ${ }^{9}$. Um estilo particular de dança requer que os atores façam uma entrada coordenada; quando irrompem no espaço cerimonial, diz-se que "vieram para fora". Supostamente, essa revelação [bringing forth] das ornamentações surpreende os espectadores em admiração.

Se as ornamentações vestem o dançarino em atributos como saúde e prosperidade, essa é mais uma revelação [bringing forth]. Pois a habilidade em conquistar proeminência se encontra nas qualidades internas, fontes de força que são a íntima preocupação dos indivíduos e de seus ancestrais, mas, em tais ocasiões, são externalizadas para escrutínio público. Mas por que a ênfase no disfarce?

Os dançarinos também dizem ter pena de suas peles, por isso as cobrem. Assim como em outras regiões da Papua Nova Guiné (e.g. Read, 1955: 266), o termo para "pele” abrange tanto a epiderme quanto a carne, o corpo assim como sua superfície. De forma geral, as pessoas falam de ornamentações como "tornar a pele boa", realçando-a de forma que pareça gorda e sólida. Um dançarino cujas decorações foram admiradas diz ser porque "minha pele estava boa". Mas as mesmas decorações também são referidas como uma cobertura. A despeito de artifícios

$7 \quad$ Embora alguém possa cumprimentar um dançarino por seu conjunto e, em retorno, receber um pequeno presente. O elogio público também pode ser dado em uma base individual (ver Strathern, A. \& M., 1971: 126), mas a plateia como um todo não se une em uma reação única em nenhum momento.

8 A reação da plateia é mais formalizada e a audiência mais seleta em performances de culto do Espírito do que nas ocasiões moka como descritas aqui.

9 Áreas cerimoniais, onde ocorrem os festivais, são "lugares externos", e um termo para fazer moka é "virar para fora" ["to turn it outward"]. 
particulares - usar uma fileira de conchas maior no peito de modo que pareça cheio - o efeito da ornamentação deveria ser o de "esconder a pele". As ornamentações são um tipo de cobertura para o corpo, as quais se impõem entre o dançarino e o espectador como se fossem uma camada que escondesse o dançarino.

Possivelmente, uma função do disfarce é submergir o indivíduo em uma identidade de grupo, o tipo de contraste ao qual Gell (1975: 192-3) se refere entre um papel público ideal (o membro de um clã) e um papel pessoal encoberto (a pessoa individual). Como os jovens homens Sepik Umeda, cujas ornamentações "oferecem uma cobertura de suposto anonimato para a indulgência... na autoexibição sexual individual" (: 193), os dançarinos hagen individuais também esperam incitar admiração para si. Mas há mais na ideia hagen de disfarce do que a ênfase em um papel ideal. $\mathrm{O}$ ato de ocultação relaciona-se ao conceito de trazer coisas para fora. Se formos buscar uma relevante teoria do corpo, como insiste Gell, então possivelmente ela se encontre na relação entre aparência física e qualidades internas. Os Hagen usam os mesmos idiomas que nós - coisas que são intrínsecas estão dentro. O fracassado [the rubbish man], afirmam, é aquele que ornamenta sua pele, mas não tem nada que valha seu nome. Deveria haver uma adequação entre as ornamentações e o homem. Portanto, uma pessoa pequena e magra ou alguém emaciado por doença ou que sofra um infortúnio pessoal com a perda de um parente evitará dançar ou ser criticado por tentar se ornamentar. Cobertura não implica encobrir um estado indesejável.

Nos assuntos cotidianos dos Hagen, o sigilo é um elemento importante, tanto no poder e na autonomia de grupos quanto de indivíduos. Em ocasiões de grandes trocas, em contraste, declarações explícitas são feitas sobre questões, de outro modo, íntimas. A riqueza é posta em cena, a força de um clã, medida por sua linha de dançarinos. Pessoas afirmam ainda que espíritos ancestrais, normalmente distanciados do indivíduo sobre quem exercem apenas uma influência invisível, fazem, na verdade, sua presença ser notada. O que é ordinariamente escondido é, então, abertamente trazido para fora. Especificamente, o que é ordinariamente escondido, dentro da pele, é o eu interior, as capacidades básicas de uma pessoa. No processo de ornamentação, o dançarino não pega emprestadas roupas para se esconder; pelo contrário, é o seu interior que é trazido para fora. Mas como o interior pode ser visível, como essas qualidades internas podem ser evidências delas mesmas? Disfarce é aqui o mecanismo da revelação. $\mathrm{O}$ eu interior é visível apenas até ao ponto em que torna invisível o corpo externo.

\section{O eu}

Este não é o lugar para uma discussão completa sobre as ideias acerca do eu. Não estou preocupada com a expressão da idiossincrasia ou personalidade ou com a projeção psicológica da identidade. $\mathrm{O}$ aspecto que parece o tema da auto-ornamentação é uma noção hagen de valor básico, uma capacidade interna de conquista. Todos os indivíduos compartilham um potencial comum; são os graus de sucesso que, aos olhos hagen, os diferenciam.

O eu interior é manifesto através do corpo, não divorciado dele. Não há uma ideia de 


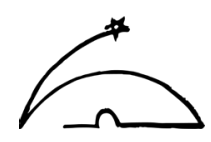

esforço em direção a um estado incorpóreo de individualidade. Se as decorações comentam sobre a relação entre interno e externo, elas não implicam uma dicotomia entre espírito/corpo ou essência/matéria de tal modo a fazer os primeiros mais cruciais à identidade pessoal do que os últimos. Pode-se dizer que o eu interior ${ }^{10}$ é o min, ou a alma (cf. Vicedom, 1943-8: II: 332f), mas, como descreve Strauss (1962: ch. 18), esse tem a natureza da força vital que permeia o corpo. Um corpo saudável é, assim, um sinal de que o min está em um bom estado (: 145). O mesmo é verdadeiro em relação ao noman, ou "mente", por vezes localizado no peito, e muito mais semelhante a um órgão do corpo do que o min. O noman é bastante interno, envolvido pelo corpo, e é uma fonte de intenção e desejo. Os Hagen contrastam o que está na pele e o que está no noman de alguém. Ninguém pode ver dentro do noman de outro, apenas adivinhar, pelo seu comportamento, quais são suas inclinações. A interpretação de sentido assenta-se nesta dicotomia: as palavras de uma pessoa provém de seu noman e revelam suas verdadeiras intenções, ou estão simplesmente "na boca"? É por meio da organização do noman, resolvendo vários desejos, que se pode mostrar propósito e capacidade de sucesso.

Há um contraste entre a apresentação do eu em circunstâncias cotidianas e naquelas ocasiões em que as ornamentações completas são usadas, uma marcada gradação de publicidade. Normalmente, um homem mantém seus desejos, intenções e bens materiais escondidos. O que ele dá a outros - compromisso, informação, dádivas - está sob o controle de seu noman. Ao passo que o conteúdo do noman sempre permanece escondido, os recursos visíveis de uma pessoa, aqueles que permite serem vistos, diz-se "estarem na pele". A pele é o ponto de contato entre a pessoa e o mundo. Assim, a vergonha envolve um enredamento do indivíduo em relações sociais, e a vergonha se manifesta na pele (Strathern, A. J., 1975a). As transações com outros são realizadas por meio da riqueza, bens e habilidades que se encontram na pele, enquanto que até que ponto elas são do verdadeiro interesse próprio do indivíduo é algo que apenas ele poderá saber internamente.

Muito valor é posto na autonomia individual. As pessoas são encorajadas a serem motivadas pelo próprio interesse assim como pelos interesses de seus associados, membros de seu clã, e assim por diante. A vida política é caracterizada pela intriga e pelo cálculo, um constante escrutínio do comportamento em busca de pistas de seus significados, envolvendo camadas de sigilo sobre os verdadeiros interesses do clã, do subclã e do indivíduo. A informação circula dentro de círculos restritos, existindo diversos tipos de recursos para deliberadamente enganar o estranho da vez. O mesmo é verdade acerca de questões financeiras. Ninguém fala abertamente sobre seus bens: eles são vaidosamente guardados da vista pública até que são criteriosamente vazados para o mundo em etapas planejadas para o máximo efeito. Demonstrações públicas de conteúdo político ou estratégias econômicas são sempre o resultado de encenação deliberada ${ }^{11}$. Um dos elementos

10 Não há nenhum substantivo abstrato generalizado para indicar "eu" na língua hagen. O conceito é representado em noman (vontade, consciência), e em uma forma duplicada do pronome pessoal que indica responsabilidade pessoal por um ato, autonomia em suas ações, e isolamento no sentido de que a pessoa está fazendo algo que não envolve outros. Outros aspectos incluem noman mbo (intelecto) e kum (desejos egoístas).

11 Ou mensurada c.f. Gell (1975: 252). Gell sugere que os Highlanders têm uma teoria econômica acerca dos 
de sucesso do moka é a revelação do quanto uma pessoa ou um grupo realmente possui. É claro, nem tudo é revelado ainda, pois a maioria dos participantes esconde algumas riquezas, mas a ética de uma exibição apoteótica é que todos os recursos são exauridos na última dádiva.

Isso lembra a prática de se manter informações secretas e valiosas na forma de verdades sagradas - a base para a iniciação ritual em algumas sociedades da Papua Nova Guiné. Os Baktaman (Barth, 1975), por exemplo, se preocupam muito com engano e revelação. Mas, em Hagen, não há um corpo formal de conhecimento que em si define a categoria de pessoa (ex. iniciados de alto nível) ${ }^{12}$. Os tipos de segredos aqui referidos são os interesses escondidos de um indivíduo e seu clã. Barth enfatiza a relatividade do conhecimento ritual entre os Baktaman (sempre poderá haver algo mais a se saber), e essa característica certamente se aplica ao conhecimento secular de questões políticas e econômicas em Hagen. É uma fonte do agnosticismo encontrado nos comentários das pessoas sobre seus pares. Os Hagen esperam que os outros classifiquem a informação que compartilham com os membros de seu clã, suas relações extraclãs, e assim por diante. Em última instância, só um homem, sozinho, sabe o que possui e o que pensa.

Ordinariamente, então, reservas são retidas, para serem produzidas por cálculo. Na ocasião de um moka de grande porte, elas são esgotadas - não há mais reservas. Os doadores deram seus porcos, dinheiro e outras coisas de valor, com a quantidade exposta para todos verem, e a efetiva contagem de itens é uma parte específica dos procedimentos. Declarações públicas sobre estatuto político são feitas nos discursos que se seguem. Mais do que isso, já argumentei, a evidência da força interna e do bem-estar dos dançarinos também é externalizada. Essas são reservas de outro tipo, a energia e habilidade que os homens colocam em suas ações. Elas dependem de e são simbolizadas por sua saúde corporal. Isso pode ser observado na solidez da carne. Se as pessoas são afligidas por doenças e infortúnios, sua carne torna-se flácida e ficam incapazes de agirem como elas mesmas.

O uso de um tal símbolo físico íntimo ressalta a vulnerabilidade que os dançarinos aparentemente sentem. Isso é indicado em várias coisas: (i) as declarações sobre os dançarinos sentirem pena de sua pele, lamentando seu próprio corpo por quererem parecer grandes e bonitos; (ii) temas autodepreciativos que passam pelas músicas cantadas em tais ocasiões ${ }^{13}$, comentando, por exemplo, sobre quão poucos e empobrecidos os doadores são; (iii) o elemento da provação: se um dançarino realmente não possui recursos internos, então suas ornamentações serão transparentes;

conteúdos corporais relacionada aos seus sistemas de intercâmbio. Preocupações com comprovação, armazenamento, aumento e redistribuição de riquezas também se encontram em preocupações dos homens acerca da conservação e distribuição adequada do sêmen. Eu estou interessada em um ponto bastante diferente: não na equação simbólica entre regulação em várias esferas, mas como o processo de regulação que envolve os Hagen em um contraste entre o eu interior e o eu exterior.

12 A informação esotérica ritual é individualmente retida, ainda que possa ser comprada ou compartilhada. Ser um expert em ritual é uma habilidade de especialista que sem nenhum status a mais.

13 Para um exemplo, ver a música $35 \mathrm{em}$ Strathern, A. J. (1974). Essa foi por mulheres, mas homens cantam refrões similares. Eles pretendem certamente serem interpretados no sentido oposto, mas a forma da coisa é interessante [but the form of the beast is interesting]. 


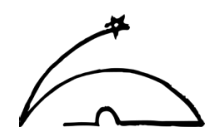

e (iv) o fato de que indivíduos usam ornamentações completas somente quando possuem apoio do grupo. É a exibição excessiva, eu sugeriria, que leva à ostentação de um modo autodepreciativo $^{14}$. Com tudo em aberto, os dançarinos renunciam aos tipos de controle que normalmente modelam suas negociações com o mundo. Por causa de toda sua paramentação, estão expostos. Andrew Strathern (1975a: 347) cita uma música cantada por mulheres durante o auge de uma excepcionalmente tensa sequência de atividades financeiras - um inovador culto de carga - em que elas se referem diretamente à vergonha que sentem na frente de todo mundo. Esse foi um evento único, e as mulheres falam mais abertamente sobre essas coisas do que os homens, mas eu tomaria como um exagero de um elemento presente em todas as exibições de grande escala. A vergonha se manifesta na pele em situações de inadequação social. Aqui a pele é coberta com símbolos de sucesso, ainda assim os dançarinos professam vulnerabilidade. Certamente o ponto é que, enquanto a pele é objeto de adorno em um sentido, os ornamentos não simbolizam forças derivadas de recursos externos, uma armadura para a pessoa; o que cobre a pele, o eu interior, torna-se ele próprio exposto.

Uma ocasião pública como um moka apoteótico é o resultado de meses de planejamento e esforço. A performance está lá para todos verem. Agora, os beneficiários saberão quão fiéis à sua palavra são os doadores: não mais o plano, mas sua execução. Há um duplo julgamento, como vimos. As alegações de poder e riqueza dos doadores se materializam na riqueza que de fato foram capazes de acumular? E será que a demonstração reflete poder intrínseco? Se as ornamentações falham em corresponder à conquista material, como quando um clã se paramenta, mas faz mal um moka, as pessoas desdenham. Sejam os presentes satisfatórios ou não, se as ornamentações são pobres, elas serão recebidas como um mau presságio. Prevê-se que os dançarinos adoecerão. Agora, doenças sob o controle de espíritos ancestrais normalmente não se manifestam no estado da pele (dessa forma a vergonha não leva à doença), mas estão relacionadas à condição do noman, ou mente. Se más ornamentações trazem doenças, eu suspeito, é porque elas indicam que o eu interior está em mau estado.

\section{Símbolos de dentro para fora}

Um breve comentário sobre dois conjuntos de símbolos seria apropriado. O primeiro é o jogo estético com elementos escuros e claros que são componentes da maioria dos conjuntos de ornamentações, mesmo onde o efeito total é projetado para enfatizar um ou outro. No pensamento hagen, geralmente, a escuridão representa coisas escondidas, cores claras coisas que são abertas, reveladas. Essa oposição abrange um contraste mais profundo, entre boas e más intenções. Desse modo, ainda que as boas intenções possam ser tão escondidas quanto as más, elas não são devidamente pensadas como escuras. Os tipos de coisas mantidas mais em segredo são questões de interesse pessoal ou do clã, envolvendo hostilidade contra estrangeiros. Em ocasiões

14 Quando estas assumem a forma de comentários sobre quão reduzido um clã é em comparação com o que era, talvez uma apelação também esteja sendo feita para adiar um julgamento final, uma pista de que em seu estado ideal o clã seria ainda mais forte. 
em que o grupo expressa seus sentimentos de agressão, saindo em combate contra inimigos ou os presenteando, o propósito geral é explícito, ainda que detalhes dos cálculos possam permanecer em segredo. A hostilidade aberta é significada em decorações escuras: sentimentos escondidos vieram à tona. Mas talvez as tintas escuras e plumas também sinalizam que, no contexto de animosidade, os homens ainda estão guardando futuras estratégias políticas. Pois se alguém exibe completamente coisas secretas, a natureza delas é transformada. O significado de ornamentações claras, brilhantes, é a declaração de que aqui não há nada ruim a esconder, que a riqueza e o bem-estar podem ser abertamente exibidos? Assim, a revelação de um bom noman emprega o oposto da escuridão. Os Hagen dizem que transmitem um senso de bem-estar ao se pintarem com ocre vermelho. (No culto do Espírito Feminino, pureza e uma mente clara - os participantes supostamente despojam-se de todo pensamento hostil em relação aos outros - são explicitamente marcadas pelo uso da cor branca.)

O segundo é a importância de ungir a pele. O óleo contribui para um efeito de brilho, fazendo o corpo parecer vestido de carne. Mas há significância em seu modo da aplicação. $\mathrm{O}$ óleo é guardado dentro de bambu ou de vasos de cabaça, de onde é derramado. Na ocasião de um festival, vários tabus sobre atividade sexual e relativos ao estado menstrual da mulher entram em vigor, e a penalidade mais frequentemente citada por não os seguir é que a cabaça secará. Pode-se ver aqui uma declaração direta acerca dos efeitos de esgotar prematuramente a reserva de alguém, que recebe uma linguagem sexual na crença concomitante de que um homem que gasta muito sêmen em constantes relações sexuais irá secar e degenerar em velhice. As ornamentações e as danças também possuem conotações sexuais explícitas - dançarinos masculinos esperam elas atraiam meninas para eles - e os tabus transmitem a mensagem de que energia não deveria ser mal gasta antes da exibição final. Assim, enquanto festas de cortejo são realizadas antes da dança final, não é até a noite posterior que meninas podem finalmente acompanhar os homens até os lugares onde estão assentados. As reservas são geralmente simbolizadas em referência a uma substância interior (sêmen) que também pode ser trazida para fora.

Não é, porém, apenas as cabaças masculinas que correm perigo de secar. Se uma mulher menstruada dança, seu próprio frasco de óleo, assim como o de seu marido, ficará esgotado. A condição da menstruação é antitética ao estado de saúde que mulheres, bem como homens, desejam exibir. Há uma proposição ainda mais geral sendo feita aqui na ênfase idiomática específica da ameaça de que o óleo não vai se derramar. Ele coagula e gruda, cai apenas em pingos. $\mathrm{O}$ ato de derramar o óleo pode ser em si um presságio. Quando a cabeça de uma noiva é ungida, se o óleo escorre livremente e em linha reta, é um sinal de que seus parentes garantirão um generoso dote, isto é, que os parentes do noivo darão toda a sua riqueza (Strathern, M., 1972: 102). Um homem descreveu como, em um grande moka, um especialista ritual para o acompanhamento de um feitiço aplicou óleo no pescoço dos homens de um clã reunidos. Ele falhou em escorrer devidamente pelo peito de dois indivíduos, e algum tempo depois ambos morreram. Talvez possamos tomar o recipiente de óleo como um símbolo em si mesmo, um vaso do qual, no momento 


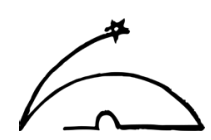

da ornamentação, o conteúdo deve fluir abundantemente. É um mau sinal para os dançarinos se ele não derramar, se não houver nada para trazer para fora.

\section{Conclusão}

Os tipos de ornamentação que discuti são cosméticas apenas em um sentido limitado. Cosméticos, para nós, realçam a pele exterior, deliberadamente atendendo a atributos físicos pessoais. Isso leva à possibilidade de uma antítese entre o corpo tão decorado e a pessoa interior ou completa. Ornamentações formais em Hagen, tenho sugerido, também se encontram no contraste entre um eu interior e exterior, mas a operação supõe uma continuidade entre esses elementos. Ornamentos são pendurados no corpo, mas a atenção dos espectadores deve estar direcionada não para o corpo em si, mas para as ornamentações enquanto uma entidade separada. Elas devem ser atraentes em si mesmas; longe de serem uma fantasia ou um presente que um ator ostenta, são símbolos dele mesmo virados do avesso.

O eu exterior, a pele, é então ornamentado com o eu interior, atributos intrínsecos. Isso é feito ao se pegar objetos do mundo exterior - penas, folhas, conchas - e anexá-los ao corpo. Objetos normalmente na pele incluem os bens materiais com os quais transações são feitas com outros. Um efeito de vestir ornamentações é, eu suspeito, a reivindicação de que as qualidades gerais de sucesso e riqueza que elas representam tornaram-se como bens materiais visíveis na pele que afetarão as relações com o mundo. Pequenas transações materiais de fato acompanham o uso de ornamentos - presentes são dados para pessoas que ajudam a prover itens, e para os homens que elogiam o efeito final, quase como se as ornamentações tivessem, elas mesmas, iniciado uma troca $^{15}$.

A dicotomia interno/externo é simplesmente uma questão do privado versus o social? Os sonhos walbiri inspirados pelos ancestrais se originam de dentro do indivíduo, mas são reproduzidos em ornamentações [designs] que atores podem manipular socialmente. "ornamentações vistas dessa maneira são elementos que atravessam as fronteiras do corpo individual (estão separados dele), mas que são constantemente trazidos de volta para dentro da experiência corporal" (Munn, 1973: 57). “Esse ‘necessário' deslocamento”, escreve Munn “do sonho interior para a realidade exterior sugere a importância de juntar a imaginação interna com o mundo externo, social, o eu interior para a ordem social exterior" (: 216). Ornamentações que ligam o corpo ao ambiente externo indicam uma ideia de continuidade entre a fonte da potência (os ancestrais, os sonhos) e suas manifestações (na fertilidade e na manutenção da vida). Os ancestrais hagen certamente auxiliam seus descendentes, e influenciam seu eu interior, mas não há fusão: em última instância, um indivíduo está em uma relação de transação com eles assim como está com o resto do mundo. Transações apoiam-se na percepção da descontinuidade, a brecha a ser transposta. Nessa

15 Uma versão concreta da ideia mais geral de que os dançarinos exibem a prosperidade futura é a de que os parceiros de intercâmbio ficarão tão impressionados pela exibição que vão se obrigar a dar belos presentes depois; diz-se que o brilho e cintilação de certos itens, especialmente conchas, e a fragrância de ocre vermelho também atraem coisas valiosas. 
sociedade orientada pelo prestígio, a distância entre potencial e conquista é também a distância entre as qualidades internas e a performance externa. Os Walbiri em ocasiões cerimoniais (: 50) podem se recobrir com ornamentações a ponto de personificarem um ancestral dentro de quem o dançarino está escondido. Em Hagen, os ancestrais estão presentes apenas se a exibição dos dançarinos for bem-sucedida, e isso depende, por sua vez, de suas transações com os espíritos serem satisfatórias: sacrifícios apropriados foram feitos, promessas foram mantidas, e assim por diante. Ademais, o ancestral está ali em apoio; o dançarino não o incorpora e nem suas decorações o representam.

Como as ornamentações hagen, os motivos walbiri fazem declarações sobre a relação entre a pessoa interna e externa. O corpo físico tanto cobre a experiência onírica contida internamente, quanto, por vezes, é coberto por ornamentações representando essas forças internas (: 216). As experiências dos dançarinos também são artefatos dos ancestrais. Assim, quando o Walbiri se reveste externamente com ornamentações, sua identidade pessoal é sobreposta por formas que retomam sua identidade social ancestral (: 190). Em Hagen, a identidade pessoal do dançarino é em certa extensão mascarada por uma identificação do clã, e é o bem-estar do clã assim como o individual que interessa aos espíritos ancestrais. Mas ainda que o clã esteja afirmando seu estado corporado [corporate], essa identidade não dota o indivíduo de uma força de ordem distinta daquela de seu poder pessoal. O indivíduo não representa a si mesmo em um aspecto transformado, derivado dos campos da potência gerada em outro plano. Ele possui apenas seus recursos para externalizar.

É por essa razão que eu penso que as ornamentações hagen dizem respeito a apresentação do eu - especialmente aqueles aspectos da pessoa relativos à capacidade e potencialidade - ao invés da identidade como tal. Toda uma gama de identidades sociais é indicada pelas ornamentações, mas essas antes idealizam do que transformam a pessoa. Portanto, ainda que, como aponta Gell (1975: 350-321), mitos sobre "mudar de pele" (a nova pele indicando uma nova personalidade) sejam comuns geralmente na Nova Guiné, incluindo Hagen, essas ornamentações não são uma segunda pele e não se referem prontamente a esse sentido.

Gell torna geral uma certa proposição sobre pintura corporal de que "é a modificação da pele, mesmo, talvez, a aquisição de uma nova pele" (1975: 320). Ora, os Umeda se adornam para representar casuares, peixes, demônios, espíritos e outras criaturas, embora, ao mesmo tempo, por causa dos atributos dessas criaturas, estejam representando ideais estereotipados de homens jovens, anciãos, e assim por diante. Por meio do disfarce de animais, Gell argumenta que dançarinos do ritual $i d a$ podem expressar certos valores e qualidades sobre si mesmos enquanto pessoas: desse modo, o casuar ressalta a possibilidade de autonomia social para um homem mais velho. Tais possibilidades podem ser expressas apenas de forma disfarçada, de modo que a identidade humana do ator é revestida com aquela do animal (: 230). Mais do que isso, a identificação do dançarino com o casuar é em si um disfarce para uma identificação mais profunda entre casuar e homem. Declarações são então feitas sobre coisas que de outra forma não podem ser expressas. 


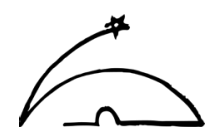

Aqui há um exemplo de se unir elementos de uma ordem diferente um do outro, de maneira que a revelação ou o reconhecimento envolve uma experiência de mistério (cf. Barth, 1975: 221-222). Há algo disso na performance de cultos espirituais dos Hagen, e parte dos procedimentos pode envolver uma suposição implícita de identidade especial (Strathern, A., 1970); quando dançarinos do culto do Espírito Feminino irrompem de seu enclausuramento, os espectadores gritam que o Espírito está vindo (Strathern, A. \& Strathern, M., 1971: 56). Houve ocasiões no passado em que outros espíritos foram personificados. Mas o sentido particular das ornamentações nesses contextos religiosos não pode ser estendido para as ornamentações como um todo. Não há nenhum mistério fundamental sobre identidade quando dançarinos se apresentam num festival moka. Eles estão simplesmente revelando recursos que normalmente ficam escondidos.

Essa é uma razão final para chamar o ato de auto-ornamentação. Pois, embora a revelação seja aos espectadores, não é para eles, como seria para uma congregação ritual. Há a esperança de admiração, de que ficarão impressionados, de que concederão prestígio - mas apenas suas opiniões, não um sentido mais geral de ser, serão modificadas pela experiência. Os dançarinos é que serão alterados. Eles serão afetados pelo que a audiência pensa, tanto pragmaticamente pelo que o sucesso ou fracasso nessa incursão influirá na próxima, quanto espiritualmente, pois seu bem-estar está em risco. O tipo de exibição que eles conseguem apresentar terá repercussões em suas relações sociais e políticas com outros, indicará o estado de recursos internos e apontará para o destino futuro. Em certo sentido, eles estão se testando, e é por si mesmos que se ornamentam.

\section{Referências Bibliográficas}

Barth, F. 1975. Ritual and Knowledge among the Baktaman of New Guinea. New Haven: Yale University Press.

Faris, J. C. 1972. Nuba Personal Art. London: Duckworth.

Gell, A. F. 1972. “Review of ‘Self-decoration in Mount Hagen””. Man n.s. (7): 683-684.

Gell, A. F. 1975. Metamorphosis of the Cassowaries. London: Athlone Press.

Greer, G. 1970. The Female Eunuch. London: MacGibbon \& Kee.

Huxley, F. 1971. “Review,'Princess Pignatelh and the Stone Age Hageners'”. Ink 13: 17.

Munn, N. D. 1973. Walbin Iconography. Ithaca: Cornell University Press.

Read, K. E. 1955. "Morality and the Concept of the Person among the Gahuku-Gama." Oceania (25): 233-282. 
Strathern, A. 1970. "The Female and Male Spirit Cults in Mount Hagen”. Man n.s. (5): 571-585.

Strathern, A. 1974. Melpa Amb Kenan, Courting Songs of the Melpa people. Port Moresby: Institute of Papua New Guinea Studies.

Strathern, A. 1975a. "Why is Shame on the Skin?". Ethnology (14): 347-356.

Strathern, A. 1975b. "Veiled Speech in Mount Hagen". In: Bloch, M. (Ed.). Political Language and Oratory in Traditional Society. London: Academic Press.

Strathern, M. 1972. Women in Between. London: Seminar Press.

Strathern, M. 1978. "The Achievement of Sex: Paradoxes in Hagen Gender-thinking”. In: Schwimmer, E. (Ed.). Symbolic Anthropology I. London: Hurst; Montreal: Mc Gill-Queen's University Press.

Strathern, A.; Strathern, M. 1971. Self-decoration in Mount Hagen. London: Duckworth.

Strauss, H. 1962. Die Mi-Kultur der Hagenberg-Stamme im Ostlichen Zentral-Neuguinea. Hamburg: Cram, de Gruyter \& Co.

Vicedom, G. F.; Tischner, H. 1943-8. Die Mbowamb. (3 vol). Hamburg: Cram, de Gruyter \& Co.

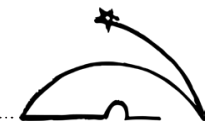

